\title{
EL IMPERIO DEL VALOR. REFUNDAR LA ECONOMÍA
}

\author{
André Orléan, L'empire de la valeur. Refonder l'économie, \\ París, Éditions du Seuil, 2011, 340 pp.
}

Pedro Ignacio Bernal*

$\mathrm{E}$ ste libro de André Orléan es un esfuerzo por construir una teoría económica que sitúe en primer lugar los vínculos e instituciones sociales. Adopta principios de la economía institucional y se inspira en la obra de antropólogos, sociólogos y filósofos para elaborar una perspectiva integral. No reniega de la economía como tal pero critica las corrientes que se apartan de la pretendida dimensión social de esta disciplina. Esa perspectiva integral no significa abandonar la economía, sino devolverle una genuina visión social. Una de sus tesis es que en una economía mercantil desarrollada el motor del intercambio es la búsqueda de liquidez, la cual es proporcionada por el dinero. A través del intercambio (de bienes y servicios, de títulos financieros, etc.), la liquidez crea los precios. El precio (o el valor, que para el autor son la misma cosa) nace de la necesidad de liquidez.

E1 libro esboza las bases de una nueva teoría del valor partiendo de la crítica de las teorías del valor marxista y walrasiana. La primera parte ("Crítica de la economía") expone esas críticas, con respecto al valor como sustancia (cap. 1), la objetividad mercantil (cap. 2) y la escasez (cap. 3). La segunda ("La institución del valor") presenta la propuesta teórica, en la que tienen un papel central el dinero (cap. 4) y el enfoque interdisciplinario (cap. 5). Y la tercera ("Las finanzas de mercado") resume su obra sobre valoración financiera (cap. 6) y la relación entre especulación y liquidez (cap. 7) que aporta elementos esenciales para su teoría del valor.

\footnotetext{
* Economista, DEA, Universidad de París XII, docente investigador de la Universidad Externado de Colombia, Bogotá, [pedro.bernal@uexternado.edu.co]. Fecha de recepción: 8 de septiembre de 2015, fecha de modificación: 29 de octubre de 2015, fecha de aceptación: 29 de octubre de 2015. Sugerencia de citación: Bernal, P. I. "El imperio del valor. Refundar la economía", Revista de Economía Institucional 17, 33, 2015, pp. 409-417. DOI: http://dx.doi.org/10.18601/01245996.v17n33.19
} 
Para Orléan, la teoría del valor marxista basada en el trabajo y la teoría neoclásica basada en la utilidad son sustancialistas, pues en ambas el valor es el efecto de una sustancia que los bienes poseen en sí mismos: la "hipótesis sustancialista", que tiende a "naturalizar" las relaciones económicas porque da prioridad a los objetos y da lugar a una "economía de dimensiones" en desmedro de la "economía de relaciones". Busca, en cambio, construir una teoría en la que las relaciones sociales de mercado tengan el lugar protagónico, y derivar de ellas el valor de las mercancías. Antes de comentar los elementos de su teoría, veamos por qué considera sustancialistas a las teorías mencionadas.

En la versión neoclásica walrasiana los bienes tienen un valor objetivo, independiente de las interacciones en el mercado, cuyo origen son las preferencias individuales, que supone exógenas. La conexión entre agentes económicos se da exclusivamente a través de la circulación de bienes, sin relaciones personales, jerarquías ni compromisos colectivos que interfieran la voluntad privada. Las preferencias son exógenas en cuanto no dependen de la voluntad de los agentes sino de su "cálculo de la utilidad”, una característica intrínseca de los bienes y, por ende, externa a los consumidores. En competencia perfecta los agentes no influyen en los precios, pues se supone una racionalidad paramétrica, no estratégica, sin negociación, regateo, acuerdos ni contratos. Es un mecanismo automático, centralizado (en el subastador), en el que los precios son la expresión sintética de la relación entre oferta y demanda, sin "fricciones ajenas al mercado". La falla esencial de esta teoría es que, entre la libertad ex ante de los actores y el equilibrio ex post del mercado, se descartan los desequilibrios porque excluye el dinero, y el subastador (el secretario del mercado) supone una centralización que no representa a la economía de mercado.

Por su parte, en la teoría marxista el mercado no es el que define el valor de una mercancía, sino al contrario, el valor de la mercancía (determinado en la producción) es el que determina la relación de intercambio. Así se ignora que el mercado conecta a compradores y vendedores, como sabía Adam Smith, pero olvidaron Marx y Ricardo, que no se interesaron en el análisis de los mercados. En Marx, la oferta y la demanda fijan el precio, más exactamente sus desviaciones con respecto al valor, y este es el que regula la relación entre oferta y demanda, el centro en torno al cual hacen variar los precios de mercado. A pesar de que Marx defendió una visión socio-histórica del capitalismo, su hipótesis sustancial del valor lo llevó a una interpretación trans-histórica del valor: se puede calcular el tiempo de trabajo 
socialmente necesario incorporado en toda mercancía, sin incorporar las relaciones sociales inherentes a los intercambios, de modo que es una magnitud "natural", ajena a las relaciones sociales. La teoría del valor trabajo (basada en la producción) descuida el intercambio, cuyo papel se reduce a manifestar un valor ya existente.

La "hipótesis mimética" que propone Orléan postula una economía de relaciones e intenta "construir un marco conceptual que piensa el valor por lo que es, no una sustancia, sino una institución sociohistórica, la institución que constituye el fundamento de la economía mercantil" (p. 44).

Según la hipótesis mimética, el valor de uso y el valor de cambio son obra de la sociedad. Los bienes que se ofrecen en el mercado cambian continuamente, en calidad y cantidad, y generan incertidumbre entre los consumidores (que por ello no son soberanos), quienes observan el entorno para buscar un modelo que seguir o imitar para orientarse. Los individuos se influyen mutuamente a través de sus decisiones y por ello las preferencias son endógenas, no exógenas. En este régimen de "mediación interna”, que Orléan denomina mimético, lo más importante no son las mercancías ni su valor (la utilidad o el contenido de trabajo), sino llenar el vacío de los individuos, los cuales imitan a otros: a sus modelos de referencia ${ }^{1}$.

El concepto de autorreferencialidad, que Orléan emplea en su obra sobre el sistema financiero, denota que los agentes del mercado deciden, en un marco de incertidumbre, sobre el rumbo de las variables básicas, en especial de los precios (p. ej., de las acciones en la Bolsa). Quienes participan en los mercados financieros tienden a decidir según lo que parece decidir el mercado, es decir, conforme a la opinión mayoritaria, "prefieren equivocarse con la multitud que tener la razón solos": el "efecto de rebaño" o polarización mimética de las preferencias que da lugar a las burbujas: el aumento del precio de las acciones es una señal o una promesa de ganancias futuras, que alienta la demanda y eleva aún más los precios, lo cual provoca más demanda y así sucesivamente. En este mercado se pasa fácilmente de ser comprador a ser vendedor y viceversa, al vaivén de la variación de precios por el gran potencial de liquidez de los títulos financieros. La oferta y la demanda se refuerzan en la misma dirección (el aumento de precios provoca más demanda, no menos), lo que Orléan (2011) llama retracción positiva, a diferencia de los mercados "normales" donde predomina la retroacción negativa (el mayor precio provoca menor demanda).

${ }^{1}$ La hipótesis mimética se basa en la antropología de Girard (1972, 1978). 
Aplica este esquema a ciertos bienes, que no se buscan por sí mismos, por su valor o utilidad intrínsecos, sino porque acaparan el deseo de la multitud, en los que la polarización de los deseos, la imitación de los demás es lo que los hace deseables. En las economías de mercado hay numerosos ejemplos de ello: vestidos de moda, bienes de prestigio, técnicas y dispositivos de comunicación como el correo electrónico y whatsapp, el teclado QWERTY. Según Orléan, esta polarización mimética también se presenta en campos como el de los idiomas, donde una lengua tiende a predominar entre los hablantes, como el inglés, por conveniencia (cuantos más la empleen más conveniente es para todos: "rendimientos crecientes de adopción"). Poco importa que una técnica o una lengua no sea la mejor (por sus cualidades intrínsecas), si acapara la atención y las preferencias de la mayoría en un proceso dependiente de la trayectoria.

Orléan resalta que la hipótesis mimética pone el intercambio en el centro del sistema conceptual: el mercado da lugar al valor e incluso a la utilidad. Generaliza el esquema aplicándolo al dinero; este no es un simple medio de cambio. Su naturaleza es institucional, de relación social, y se impone como signo de valor, no por sus cualidades intrínsecas, sino en un proceso acumulativo, mimético, con rendimientos crecientes de adopción. E1 dinero ocupa un lugar central en su concepción del valor porque para él una economía mercantil es necesariamente una economía monetaria y la moneda, específicamente la búsqueda de liquidez, concentra los deseos de los agentes, más allá de satisfacer sus necesidades (utilidad del consumidor). La utilidad del dinero, su liquidez, no es una cualidad intrínseca, independiente del comportamiento de los demás, sino de carácter relacional, basada en la confianza, la representación colectiva y las expectativas. Tampoco es exógena, independiente del comportamiento recíproco de los agentes. Cuando todos aceptan la moneda, "su capacidad" para prestar el servicio de liquidez se les impone, asume la apariencia de una cualidad intrínseca y hace olvidar que depende del marco institucional, del convenio necesario para que esta mediación externa prevalezca.

La búsqueda de dinero como resultado del intercambio da nuevo significado al valor; la fórmula de la circulación M-D-M' (el dinero como medio de cambio) se convierte en su inversa: D-M-D', que refleja la convergencia de los deseos en el objeto monetario (Aglietta y Orléan, 1990,77-78). Al hipostasiar el intercambio entre mercancías, es decir, los precios relativos, las teorías neoclásica y marxista abstraen el dinero, como si fuese un velo detrás del cual ocurre lo real. Esta omisión las lleva a tratar el intercambio desde afuera, de modo que este 
no determina el valor. Por ello el enfoque económico suele analizar el intercambio a partir del trueque, y cuando introduce el dinero, solo lo hace como medio de cambio; así excluye el intercambio propiamente dicho (las transacciones monetarias) pues omite la influencia de las circunstancias concretas del intercambio y del dinero en la "economía real", es decir, lleva a pensar que el dinero es neutral.

Orléan revisa la noción de escasez en el marco de su hipótesis mimética, y se apoya en autores que adoptan la perspectiva relacional. De Veblen (1970) toma la idea del consumo y la posesión de bienes que confieren prestigio y superioridad social, y provocan luchas competitivas, celos y envidia, así como una escasez de tipo eminentemente social, mimético, rivalitario y endógeno. El "derroche ostensible" puede llevar a poseer bienes sin utilidad alguna. Y la escasez surge en una organización social específica, instituida por el mercado, que hace depender la posición y la importancia de cada quien de su capacidad para adquirir objetos. La escasez depende de las instituciones sociales, no de la actitud o la voluntad de los individuos.

De Sahlins (1976) toma la idea de la escasez como relación social que se expresa en una toma de distancia estructural de los objetos para hacerlos deseables. La economía de mercado se basa en la escasez relativa, que se renueva continuamente: el aumento de la producción en respuesta a las necesidades, lejos de satisfacer a los consumidores y reducir la brecha entre demanda y oferta, los incita a obtener nuevos bienes. Conforme a Dumouchel (1979), la economía de mercado se enfrenta a una circularidad: las necesidades determinan la cantidad de bienes necesarios y la cantidad de bienes producidos determina las necesidades, de modo que es imposible reducir la brecha entre necesidades y recursos. La escasez jamás se reduce, se reproduce continuamente; las preferencias no están dadas, son producto de las relaciones de intercambio.

Para pensar el valor, Orléan adopta una visión interdisciplinaria que se nutre de la sociología, la antropología y la filosofía. Y propone refundar la economía retomando los aportes de las demás ciencias sociales. Toma muy en serio la visión sociológica del valor, más precisamente de los valores, que pueden ser morales, éticos, religiosos, etc. Para Simmel, el dinero es "un derecho que obtiene su efectividad del deseo de los otros y no de un compromiso formal que obligaría a todos los actores a aceptarla en toda circunstancia" (1987, citado por Orléan, 192-193). Lordon estudia el dinero desde un punto de vista spinozista. La confianza en el dinero es el fundamento del valor económico y "la convergencia mimética, por el hecho de que realiza 
la promesa de la liquidez, valida ex post las pretensiones del objeto monetario. Su liquidez absoluta confirma lo justo de su representación" (2010, citado por Orléan, 197-198). Durkheim (1967, 1993 y 2003) hace énfasis en el "sentimiento colectivo" cuando estudia el fenómeno religioso y lo define como algo que se funda en la vida en comunidad, que no es la simple suma de las conciencias y sentimientos individuales, sino algo que solo se cristaliza en instancias colectivas. En el totemismo, por ejemplo, el culto se dirige en apariencia a los objetos, pero en realidad se enfoca en ese principio común, la fuerza anónima e impersonal que se encuentra en cada ser, sin confundirse con él.

El paralelo con el dinero es claro: los objetos (como el dinero) no poseen en sí mismos las cualidades que les atribuyen los "creyentes", pero esas cualidades corresponden a una realidad, la que la sociedad ve en ellos; no residen en los objetos sino que se las da la sociedad, a través del afecto común y la polarización mimética. Para Orléan la objetividad del símbolo solo expresa la exterioridad del fenómeno (social o religioso), tanto en el aspecto religioso como en el monetario. Esta visión se basa en la idea de una autoridad específica de lo social, del poder de la multitud, que actúa sobre cada individuo imponiéndole formas colectivas de actuar, pensar y sentir, llamadas instituciones. En el caso del dinero, esta autoridad toma la forma de poder de compra, que se cristaliza en ciertos objetos llamados riqueza.

Por su parte, Castoriadis revisa la crítica de Marx a Aristóteles, quien se pregunta qué hay de igual o qué permite igualar cosas cualitativamente distintas ( 5 camas $=1$ casa). Aristóteles parte de que no hay intercambio sin igualdad, ni igualdad sin conmensurabilidad; $\mathrm{y}$ argumenta que dos cosas sensiblemente distintas no son conmensurables entre sí, a lo que Marx responde que lo igual/idéntico, la sustancia común, es el trabajo humano. Y sentencia que Aristóteles fracasó en su intento de resolver el problema del valor (Castoriadis, 1978, 249-250). Según Castoriadis: "La reducción que se hace en la práctica, no es la reducción de todos los trabajos a trabajo simple; es la 'reducción' de todos los trabajos a dinero (o a otro 'equivalente general' o numerario socialmente instituido), lo que no es en absoluto la misma cosa, algo que ya sabíamos sin 'teoría del valor', lo que la 'teoría del valor' debería explicar; en lo cual se basa para existir como teoría” (ibíd., 261). Lo que respalda la posición de Orléan. Castoriadis argumenta:

Aristóteles no dice que la posición de igualdad/identidad [...] de los productos - por ende, de los trabajos- es un 'expediente para las necesidades prácticas' [...] Dice que los individuos (también sus trabajos y sus productos) son 'muy distintos y no iguales' y que 'hay que igualarlos' para que pueda haber intercambio y sociedad. Esta igualación es la obra del nomos, de la ley, de la 
institución social-histórica [...] la igualación (de los objetos, de los trabajos, de los individuos) es cada vez realizada suficientemente para la necesidad/uso de la sociedad, para que la sociedad se sostenga como conjunto. [La igualación] jamás puede ser verdadera igualdad y conmensurabilidad matemática; y ello es la evidencia misma (ibíd., 268).

En una economía mercantil desarrollada se tiende a una unidad monetaria, la que implica producir una liquidez última admitida universalmente por los agentes. Para Orléan, lo que permite la coordinación mercantil es el dinero, no los precios. La economía de mercado surgió a la par de una definición del valor reconocida por todos, lo que hizo posible comparar directamente el valor económico porque la referencia monetaria era única, y dio origen a un mundo adaptado al cálculo, la condición para un comportamiento racional.

Orléan recalca que el valor no se debe confundir con el "precio justo”. Lo objetivo son los movimientos monetarios; cuanto más intenso es el intercambio de mercado, mayor es el dominio social del dinero. El precio de una mercancía depende de la lucha entre productores y compradores; $y$ no es necesario postular un precio único, pues puede tener distintos precios en el mismo lugar, sin que el valor pierda objetividad. Este problema se debe estudiar a partir de la competencia $\mathrm{y}$ de los mecanismos de intercambio.

\section{COMENTARIOS FINALES}

La principal idea del libro es que la economía de mercado depende totalmente del dinero, de la búsqueda continua y unánime de liquidez, la cual da objetividad al valor: el valor de mercado (el precio, exactamente el precio nominal) surge por la búsqueda incesante de liquidez. Distingue así entre forma del valor, que depende de la liquidez, y nivel de los valores (precios) en el mercado, que depende de la competencia, de la oferta y la demanda. Así evita el problema de determinar el "precio justo".

Todo parece quedar subsumido en la búsqueda de liquidez per se, que se expresa en la función del dinero como reserva/acumulación de valor, símbolo de riqueza social, que se impone a la de medio de cambio. Este sesgo del autor se debe a que él generaliza sus observaciones sobre las finanzas y las extiende a la economía en su conjunto; y parece desconocer el papel de la producción, el trabajo y la creación de valores materiales, o lo subordina a la circulación monetaria. Para explicar la subordinación del trabajo al dinero, Aglietta y Orléan $(1990,244)$ argumentan que el orden mercantil se instauró cuando se estableció un poder monetario privado, que modificó el ejercicio 
de la soberanía monetaria y desarrolló con desmesura la producción de objetos. Cuando la acumulación privada de dinero se convirtió en fuerza motriz del deseo, el trabajo se "liberó" de las ataduras personales y estatales. Como señalan, reconociendo la paternidad de Marx, la inversión, mediante la cual la circulación mercantil capitalista se apoderó de la producción, surgió en Europa desde el siglo XIII. La producción empezó a tener como mira la circulación, y la forma del intercambio redefinió el valor de uso dándoles un sentido social a los objetos, como lo resume la fórmula de Marx: D-M-D'; en la que las relaciones mercantiles imponen su temporalidad a la producción: el ritmo de flujos y reflujos de dinero, el movimiento de mercancías y de obligaciones contractuales.

Con respecto al papel del trabajo, Aglietta y Orléan, basados en Benetti y Cartelier (1980), afirman que el salario es una dependencia monetaria que somete a una categoría social formada por individuos en principio intercambiables, el trabajo asalariado, a las unidades privadas que disponen de iniciativa monetaria: las empresas. La relación salarial (trabajo contra salario) es subsumida en un contrato privado. El costo de producción se convierte en referencia para la competencia entre capitalistas, y la ganancia es arma de supremacía en esa competencia (ibíd., 245-246).

Pese a los sesgos del libro que se reseña, su autor pone de relieve un aspecto visible de la economía actual, en la que se impuso un capitalismo rentista que incorpora en sus activos fondos de pensiones y excedentes monetarios de los países emergentes, y traslada cuantiosas colocaciones financieras en pos de la máxima utilidad posible, en desmedro de la eficiencia productiva y del empleo de millones de asalariados, que se vuelven piezas prescindibles cuando la rentabilidad financiera así lo exige.

\section{REFERENCIAS BIBLIOGRÁFICAS}

1. Aglietta, M. y A. Orléan. La violencia de la moneda, México, D. F., Siglo XXI, 1990.

2. Benetti, C. y J. Cartelier. Marchands, salariés et capitalistes, París, Maspero, 1980.

3. Castoriadis, C. "Valeur, égalité, justice, politique de Marx à Aristote et d'Aristote à nous", C. Castoriadis, Les carrefours du labyrinthe, París, Éditions du Seuil, 1978.

4. Dumouchel, P. "L'ambivalence de la rareté", P. Dumouchel y J.-P. Dupuy, dirs., L'enfer des choses, París, Éditions du Seuil, 1979.

5. Durkheim, É. "Représentations individuelles et représentations collectives", Sociologie et philosophie, Paris, PUF, 1967.

6. Durkheim, É. Les règles de la méthode sociologique, Paris, PUF, 1993. 
7. Durkheim, É. Les formes élémentaires de la vie religieuse. Le système totémique en Australie, París, PUF, 2003.

8. Girard, R. La violence et le sacré, París, Grasset, 1972.

9. Girard, R.; J.-M. Oughourian y G. Lefort. Des choses cachées depuis la fondation du monde, París, Grasset, 1978.

10. Lordon, F. Capitalisme, désir et servitude. Marx et Spinoza, París, La Fabrique, 2010.

11. Orléan, A. "Pourquoi tant de crises?", Alternatives Économiques Horssérie 87, Les marchés financiers, primer semestre de 2011, pp. 28-30.

12. Sahlins, M. Âge de pierre, âge d'abondance. L'économie des sociétés primitives [1974], París, Gallimard, 1976.

13. Simmel, G. Philosophie de l'argent [1900], París, PUF, 1987.

14. Veblen, T. Théorie de la classe de loisir [1899], París, Gallimard, 1970. 